\title{
Advanced Technique to Increase Retention of All Metal and Porcelain Fused to Metal Crowns to Cast Post and Core Restorations
}

\author{
Mohammed A. Al Rashed ${ }^{1}$, Mansour S. Alkanani ${ }^{2}$, Jaser Alghamdi ${ }^{3}$, Khalid Alshehri ${ }^{4}$, Faisal F. Alzeghaibi ${ }^{5 *}$ \\ ${ }^{1}$ BDS, MSc, JBP Consultant, Prosthodontics Division, King Abdulaziz Dental Center - King Abdulaziz Medical City, Ministry of \\ National Guards - Health Affairs, Riyadh, Saudi Arabia \\ ${ }^{2}$ BDS, Ministry Of Health, Riyadh, Saudi Arabia \\ ${ }^{3}$ DMD, College of Dentistry, King Saud bin Abdulaziz University for Health Sciences, Riyadh, Saudi Arabia \\ ${ }^{4}$ BDS, Prosthodontics Division, King Abdulaziz Dental Center - King Abdulaziz Medical City, Ministry of National Guards - Health \\ Affairs, Riyadh, Saudi Arabia \\ ${ }^{5}$ DMD, Prosthodontic resident, College of Dentistry, King Saud bin Abdulaziz University for Health Sciences, Riyadh, Saudi Arabia
}

DOI: $\underline{\text { 10.36348/sjodr.2022.v07i01.006 }}$ | Received: 15.12.2021 | Accepted: 16.01 .2022 | Published: 21.01 .2022

*Corresponding author: Faisal F. Alzeghaibi

DMD, Prosthodontic resident, College of Dentistry, King Saud bin Abdulaziz University for Health Sciences, Riyadh, Saudi Arabia

\section{Abstract}

Short clinical crowns are more prone to crown dislodgment. Therefore, extra retentive features may be warranted. Though, classic retentive techniques are not always possible to apply in fixed prosthodontics. Hence, it may be beneficial to utilize non-conventional methods to enhance retention in situations where retention cannot be obtained from primary and secondary retentive factors. This article describes a modified technique to increase cast metal and porcelain fused to metal crowns' retention to cast post and core by using a horizontal retentive pin and hole to lock the crown to the cast post and core.

Keywords: Retention, cast, post, core, crown, technique.

Copyright $\odot 2022$ The Author(s): This is an open-access article distributed under the terms of the Creative Commons Attribution 4.0 International License (CC BY-NC 4.0) which permits unrestricted use, distribution, and reproduction in any medium for non-commercial use provided the original author and source are credited.

\section{TEXT}

Retention is a fundamental form of tooth preparation. The axial wall surfaces are considered as one of the primary retentive features by their length, parallelism, and surface area that vastly impact crown's ability to resist dislodgment and movement. Teeth that lack the primary retentive features can be enhanced with having secondary internal retentive features as, grooves, boxes, vertical pin holes, and horizontal retentive posts.

Moreover, increasing surface roughness of restorations as well as the use of adhesive cements are other methods to be used.

Unluckily, in many clinical cases, the retentive factors are not always available leading to a compromised retention. Hence, it may be beneficial to utilize non-conventional methods to increase retention in certain clinical scenarios. This article describes a modified technique to increase crown retention to cast post and core by using a horizontal retentive pin to lock the crown to the cast post and core.

\section{TECHNIQUE}

1. Prepare the root canal for cast post and core.

2. Make an impression with a plastic impression post (ParaPost ${ }^{\circledR}$ XPтм; Coltene, Whaledent Int, New York, NY) for the fabrication of a cast post and core utilizing the indirect technique.

3. Create a wax pattern for the post and core incorporating a horizontal plastic burnout or impression post (ParaPost ${ }^{\circledR}$ ХРтм; Coltene, Whaledent Int, New York, NY) within the core (Fig 1).

4. Separate and remove the horizontal post from the core pattern, and complete the investing, casting, and finishing procedures in a conventional manner for the post and core without the horizontal pin patterns.

5. Verify the cast post and core fit clinically, then cement it (Fig 2). 
6. Make a hole in the tray in order to fit the plastic impression post (ParaPost ${ }^{\circledR}$ XP'M; Coltene, Whaledent Int, New York, NY).

7. Take an impression of the cemented cast post and core with the plastic impression post (ParaPost® XРтм; Coltene, Whaledent Int, New York, NY) inserted horizontally into the cast post and core (Fig 3).

8. Detach the plastic impression post then remove the impression after the material has set (Fig 4).

9. Complete the investing, casting, and finishing of the horizontal retentive pin in a conventional manner.

10. Seat the cast horizontal pin in its housing within the stone die, then wax-up the crown pattern, then remove the cast horizontal pin, and complete the investing, casting, and finishing procedures of the crown in a conventional manner.

11. Verify the fit of the crown clinically over the cast post and core and evaluate contacts, margins and occlusion.

12. Cement the two pieces simultaneously, starting with the crown, and followed with the horizontal retentive pin by inserting it through the crown and core

13. When the cement is fully set, remove excess cement, and cut the excess part of the retentive pin.

14. Finish and polish in a conventional manner.

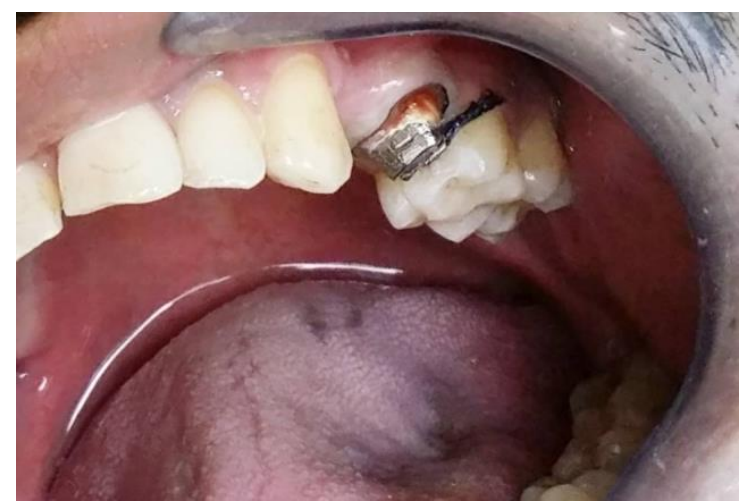

Figure 1: Wax pattern for the post and core with a horizontal plastic burnout post

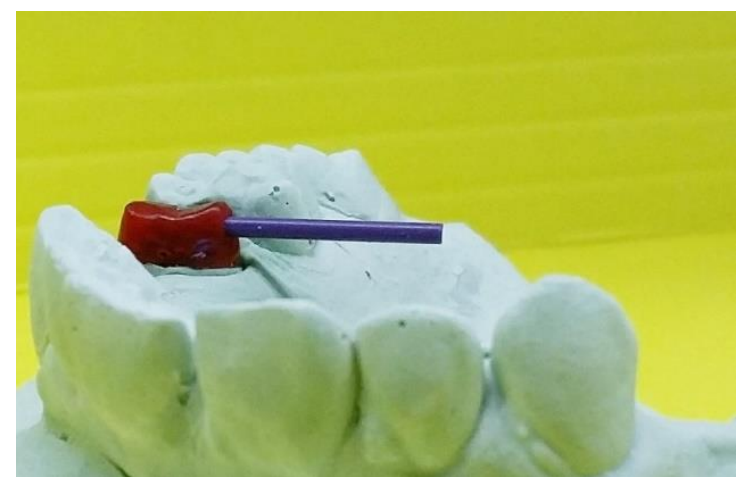

Figure 2: Cast post and core cemented in the patient's mouth

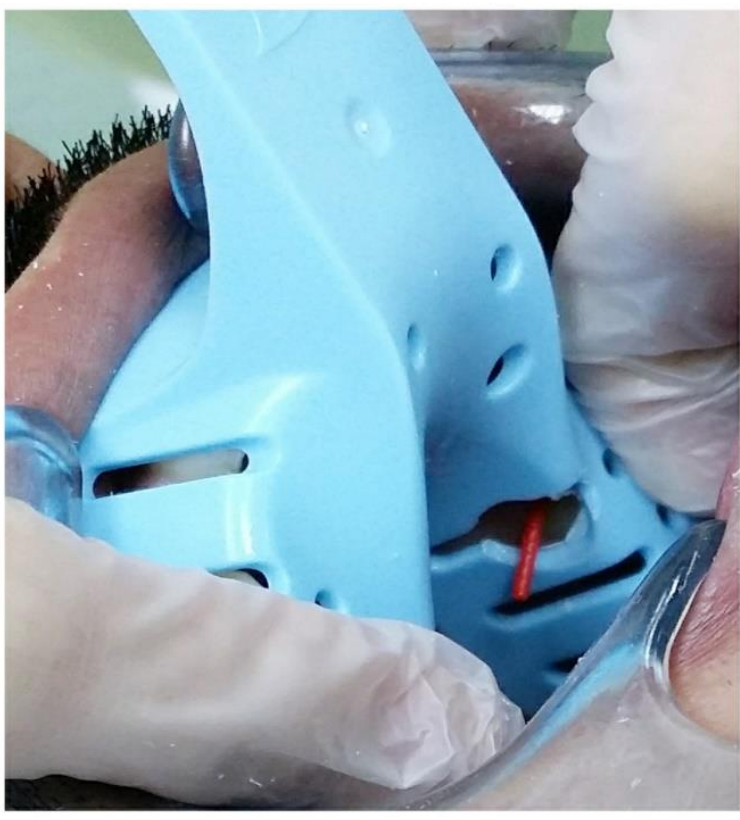

Figure 3: Plastic impression post inserted into the cast post and core prior impression to verify fitness

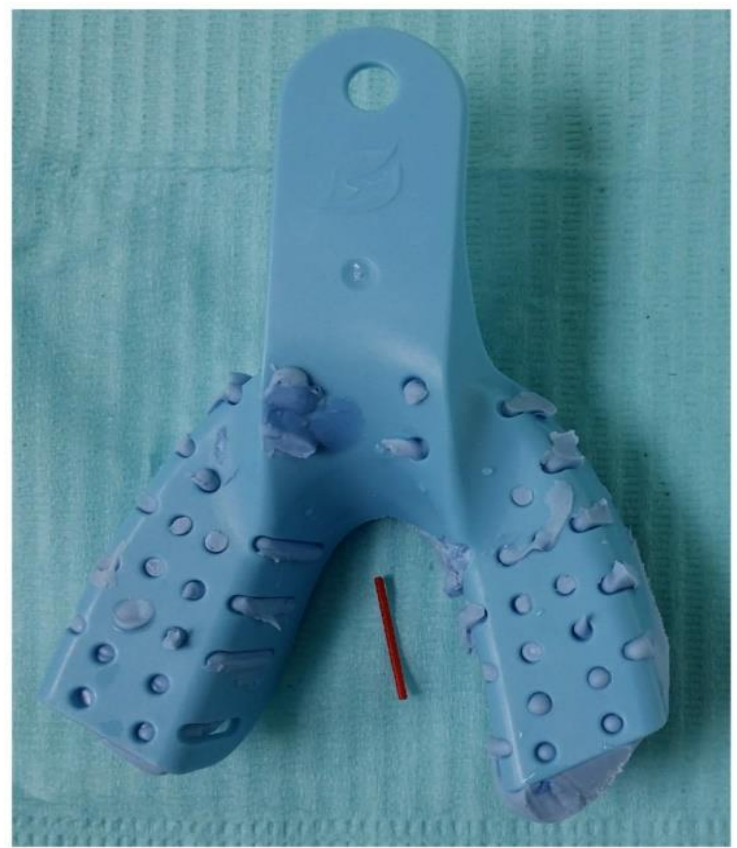

Figure 4: After removal of the plastic impression post and the impression from the patient's mouth

\section{DISCUSSION}

This article describes a modified technique to increase retention in endodontically treated teeth that require cast post and cores. In teeth with limited interocclusal space and does not have long parallel axial walls to provide retention of the crown, this modified technique is useful. The horizontal retentive pin seals the vent hole created in the crown as well as it prevents its dislodgment. 
Previous literature has found that including a vent hole in a crown can improve crown seating, decrease occlusal cement thickness and contribute to additional retention.

In order to seal the vent holes, both direct and indirect techniques are available. One of the methods described by Basset suggested fabricating a casted pin that fits into crown vent holes to seal them.

In a previous technique, the cast retentive horizontal pin acts to seal the vent hole in the crown as it increases the retentive features. Likewise, this current technique incorporates all these features, yet the cast retentive horizontal pin and the crown will have better fit to the cast post and core. As a result of, fabricating the cast horizontal retentive pin to the cemented cast post in two different steps not altogether. The authors believe this will decrease the margin of error as well as possess a better fit.

\section{REFERENCES}

- Gilboe, D. B., \& Teteruck, W. R. (2005). Fundamentals of extracoronal tooth preparation. Part I. Retention and resistance form. Journal of Prosthetic Dentistry, 94(2), 105-107.

- Amarnath, G. S., Pandey, A., Prasad, H. A., \& Hilal, M. (2015). Comparative evaluation of enhancing retention of dislodged crowns using preparation modifications and luting cements: An in-vitro study. Journal of international oral health: JIOH, 7(8), 47-51.

- Vinaya, K., Rakshith, H., Krishna Prasad, D., Manoj, S., Sunil, M., \& Naresh, S. (2015). To Evaluate \& Compare Retention of Complete Cast Crown in Natural Teeth Using Different Auxiliary Retentive Features with Two Different Crown
Heights-An In Vitro Study. International journal of biomedical science: IJBS, 11(2), 99-106.

- Marker, V. A., Miller, A. W., Miller, B. H., \& Swepston, J. H. (1987). Factors affecting the retention and fit of gold castings. The Journal of prosthetic dentistry, 57(4), 425-430.

- Faisal, F. A., Alrashid, R. A., Shahad, E. Q., \& Mohammed, A. (2019). A technique to increase retention of all metal and porcelain fused to metal crowns to cast post and core restorations. International Journal of Medical Research \& Health Sciences, 8(10), 98-101.

- Ayad, M. F., Rosenstiel, S. F., \& Salama, M. (1997). Influence of tooth surface roughness and type of cement on retention of complete cast crowns. The Journal of prosthetic dentistry, 77(2), 116-121.

- Stamatacos, C., \& Simon, J. F. (2013). Cementation of indirect restorations: an overview of resin cements. Compendium of continuing education in dentistry (Jamesburg, NJ: 1995), 34(1), 42-44.

- $\quad$ Pilo, R., Cardash, H. S., Baharav, H., \& Helft, M. (1988). Incomplete seating of cemented crowns: a literature review. The Journal of prosthetic dentistry, 59(4), 429-433.

- Cooper, T. M., Christensen, G. J., Laswell, H. R., \& Baxter, R. (1971). Effect of venting on cast gold full crowns. The Journal of prosthetic dentistry, 26(6), 621-626.

- Van Nortwick, W. T., \& Gettleman, L. (1981). Effect of internal relief, vibration, and venting on the vertical seating of cemented crowns. The Journal of prosthetic dentistry, 45(4), 395-399.

- Bassett, R. W. (1966). Solving the problems of cementing the full veneer cast gold crown. The Journal of Prosthetic Dentistry, 16(4), 740-747. 